\title{
ANALISIS KOHERENSI PADA NOVEL GURU AINI KARYA ANDREA HIRATA
}

\author{
${ }^{1}$ Dhevi Septi Silvia, ${ }^{2}$ Fikri Maulana Syiba, ${ }^{3}$ Nur Aida Rohman \\ ${ }^{123}$ Universitas Muhammadiyah Tangerang \\ Corresponding Email: dhevi357@yahoo.co.id
}

Received: $22^{\text {nd }}$ of March 2020, Accepted: $6^{\text {th }}$ May 2020, Published: $23^{\text {rd }}$ of June 2020

\begin{abstract}
Abstrak
Tujuan penelitian ini adalah mendeskripsikan hubungan koherensi yang digunakan untuk membangun keutuhan wacana tulis dalam novel Guru Aini karya Andrea Hirata. Jenis penelitian ini menggunakan pendekatan kualitatif dengan metode penelitian analisis isi. Sumber data yang digunakan dalam penelitian ini adalah novel Guru Aini karya Andrea Hirata, terdiri dari dua puluh lima bab yang diterbitkan oleh PT Bentang Pustaka, Yogyakarta pada tahun 2020. Data penelitian ini menggunakan kutipan yang ada dalam novel Guru Aini karya Andrea Hirata. Berdasarkan hasil penelitian dapat disimpulkan bahwa hubungan koherensi yang digunakan untuk membangun keutuhan wacana terdiri atas (1) Hubungan Pertentangan, (2) Hubungan Generik-spesifik, (3) Hubungan Perbandingan, (4) Hubungan Sebab-akibat, (5) Hubungan Tujuan, (6) Hubungan Rujukan.
\end{abstract}

Kata kunci: Koherensi; Novel Guru Aini; Wacana Tulis

\begin{abstract}
The purpose of this study is to describe the coherence relationship used to build the integrity of discourse of writing in the Aini Teacher novel by Andrea Hirata. This type of research uses a qualitative approach with the content analysis research method. The data source of this research is Aini Teacher novel by Andrea Hirata, consisting of twenty five chapters published by PT Bentang Pustka, Yogyakarta in 2020. This research data uses excerpts in Aini Teacher novel by Andrea Hirata. Based on the results of the study it can be concluded that the coherence relationship used to build the integrity of the discourse consists (1) conflicting relationship, (2) specific-generic relationship, (3) comparison relationship, (4) causality, (5) goal relationship, (6) referral relationship.
\end{abstract}

Keywords: Coherence, Aini Teacher Novel, Written Discourse

Copyright (C) 2020 Dhevi Septi Silvia, Fikri Maulana Syiba, Nur Aida Rohman

\section{PENDAHULUAN}

Bahasa merupakan alat komunikasi baik secara lisan maupun tulisan. Dalam berbahasa seringkali masyarakat menggunaan rangkaian kalimat yang saling berhubungan dan membentuk ikatan makna yang berkaitan antar kalimat baik lisan atau tulisan. Wacana adalah satuan bahasa terlengkap, tertinggi, dan terbesar di atas kalimat dan klausa dengan kohesi dan koherensi. Wacana merupakan media komunikasi berbentuk lisan maupun tulisan yang dapat dipahami oleh komunikator (pembicara/penulis) dan komunikan (penyimak/pembaca) (Goziyah, 2018: 2). Suatu wacana harus memiliki keutuhan struktur. Struktur yang utuh memiliki keterpaduan antar kalimat, paragraf dan makna-makna yang terkandung didalamnya. Keterpaduan makna dalam paragraf dapat dilihat dari kekoherensiannya. Hal ini di dukung oleh pendapat dari Palupi (2013) yang menyatakan bahwa wacana yang padu adalah wacana yang 
isinya memiliki satu topik dan menunjukan kohesif dan koheren sehingga mudah dipahami oleh pembaca.

Tujuan dari penelitian ini adalah mendeskripsikan hubungan koherensi yang ada pada novel. Dalam sebuah wacana baik lisan maupun tulisan hubungan koherensi antar kalimat dalam membentuk kesatuan kalimat dan klausa sangat penting untuk menghasilkan ikatan makna yang koheren. Dengan tercapainya tujuan penulisan berupa makna yang hendak disampaikan penulis, maka tulisan yang dibuatnya menjadi bernilai dan memberi wawasan pada pembaca. Menurut Djajasudarma (2010) koherensi merupakan keterkaitan antara bagian yang satu dengan bagian yang lainnya sehingga kalimat tersebut mempunyai kesatuan makna yang utuh. Adapun koherensi menurut Arifin E. Zaenal,7 et al koherensi adalah pertalian di antara kalimat yang satu dan kalimat yang lain sehingga kalimat-kalimat itu membangun kesatuan makna yang utuh. Jadi, koherensi adalah keterpaduan antar kalimat yang membentuk makna yang utuh dalam suatu paragraf. Sedangkan menurut Goziyah (2018) sebuah wacana yang kohesif dan koherensi dapat juga dibuat dengan bantuan berbagai aspek semantik, diantaranya : (1) menggunakan hubungan pertentangan pada kedua bagian kalimat yang terdapat dalam wacana, (2) menggunakan hubungan generik-spesifik atau sebaliknya.

Generik-spesifik ini untuk menciptakan keutuhan wacana, (3) menggunakan hubungan perbandingan atara isi kedua bagian kalimat atau isi antara dua buah kalimat dalam satu wacana. Piranti perbandingan digunakan untuk menunjukan adanya hubungan persamaan atau perbedaan antara bagian yang satu dengan bagian yang lain, (4) menggunakan hubungan sebab akibat di atara isi kedua bagian kalimat atau isi antara dua buah kalimat dala satu wacanaatau sebab akibat terjadi apabila salah satu proposisi menunjukan penyebab terjadinya suatu kondisi tertentu yang merupakan akibat atau sebaliknya, (5) menggunakan hubungan tujuan di dalam isi sebuah wacana, (6) menggunakan hubungan rujukan yang sama pada dua bagian kalimat atau pada dua kalimat dalam satu wacana. Selaras dengan itu Utami (2012) berpendapat bahwa pengertian koherensi tidak terletak pada bahasa, keutuhan wacana lebih banyak ditentukan oleh kesatuan maknanya sedangkan kesatuan makna hanya terjadi bila dalam wacana tersebut terdapat sarana-sarana koherensi yang mampu mempertalikan kalimat-kalimat dalam wacana. Elfiana dan Farkhan (2018) juga menyebutkan bahwa sebuah wacana dapat dikatakan koheren jika bagian-bagiannya menyatu bersama karena adanya relasi koherensi yang jelas, baik yang ditandai secara eksplisist maupun implisit yang harus diidentifikasikan oleh pembaca secara mandiri. Relasi koherensi juga merupakan bagian dari representasi mental pembaca yang 
dibangun berdasarkan teks sehingga dapat menemukan relasi koherensi semantik atau pragmatik antarunit guna mengungkapkan proposisi, baik secara sederhana maupun kompleks.

Wacana terbagi menjadi dua yaitu wacana lisan dan wacana tulisan. Salah satu contoh wacana tulisan adalah novel. Novel merupakan wacana tulis yang paling digemari masyarakat terutama remaja. Menurut Masnuatul Hawa (2014) novel adalah sebuah karya sastra yang berusaha menampilkan gambaran kisah hidup yang diangkat dari realita permasalahan yang terjadi di masyarakat secara umum dan di dalamnya banyak mengandung nilai-nilai yang dianggap baik dan patut dijadikan tauladan bagi para penikmatnya atau pembacanya. Tulisan dalam novel harus padu agar pembaca dapat memahami makna yang terkandung di dalamnya. Kekoherensian dalam sebuah novel dapat menjadikannya sebagai bacaan yang layak dan bernilai, serta dapat memudahkan pembaca untuk memahami pesan yang ingin disampaikan penulis.

Pada penelitian ini, peneliti tertarik untuk meneliti hubungan koherensi dalam novel Guru Aini karya Andrea Hirata. Novel Guru Aini merupakan prekuel dari novel Orang-orang Biasa yang terbit di awal tahun 2019. Novel tersebut menceritakan tentang perjalanan seorang mahasiswi lulusan terbaik Desi Istiqomah dalam mencapai cita-cita dan tujuan hidupnya sebagai guru matematika di Ketumbi, salah satu kecamatan di Kabupaten Tanjong Hampar. Desi berjanji pada dirinya untuk tidak mengganti sepatu pemberian ayahnya sampai ia menemukan seorang siswa yang pandai matematika seperti dirinya. Guru Aini merupakan novel ketujuh karya Andera Hirata yang diterbitkan pada tahun 2020. Andrea Hirata adalah pemenang beberapa penghargaan sastra internasional seperti pemenang pertama New York Book Festival 2013 untuk The Rainbow Troops, Laskar Pelangi edisi Amerika, penerbit Farrar, Straus \& Giroux, New York, kategori General Fiction serta pemenang pertama Buchawards 2013, Germany untuk Die Rengenbogen Truppe, Laskar Pelangi edisi Jerman, penerbit Hanser-Berli. Hirata juga pemenang seleksi short story, majalah sastra terkemuka di Amerika, Washington Square Review, New York University, edisi Winter/Spring 2011 untuk short story pertamanya Dry Season. Bersama nobelis sastra Orhan Pamuk dan Nadine Gordimer, esai karya Hirata berjudul View from My Window terpilih untuk buku Windows of The World, 50 Writers 50 View, Matteo Pericoli, Penguin, New York. Tahun 2010, Hirata mendapat beasiswa Pendidikan sastra di IWP (International Writing Program), University of Lowa, USA. Tahun 2015, Hirata mendapat gelar Doctor Honoris Causa di bidang sastra dari University of Warwick, United Kingdom. Karya-karya original Hirata dalam bahasa Indonesia sampai tahun 2019 yaitu; Laskar Pelangi, Sang Pemimpi, Buku Besar Peminum Kopi, Ayah 
dan Sirkus Pohon, Orang-orang Biasa, Mozaik-mozaik Terindan Sebelas Patriot, Guru AiniPrekuel Novel Orang-Orang Biasa. Literatur yang digunakan Andrea Hirata memiliki kekhasan yang tidak dmiliki penulis lain serta kohesi dan kohernsi yang kuat. Hal ini dibuktikan melalui novelnya Laskar Pelangi yang telah diterbitkan ke 25 versi bahasa asing, diedarkan di lebih dari 130 negara, menjadi referensi di berbagai sekolah dan Lembaga di luar negeri untuk studi tentang Pendidikan, sastra dan budaya Indonesia, dan menjadi buku pertama International bestseller dari Indonesia. Dengan banyaknya karya Andrea Hirata yang mendunia nenbuat peneliti termotivasi untuk menjadikan novel terbarunya berjudul Guru Aini sebagai bahan kajian penelitian guna menarik lebih dalam penggunaan bentuk koherensi dalam novel tersebut.

Penulis berharap penelitian ini akan memberikan wawasan pada pembaca sebagai bagian dari pembelajaran mengenai hubungan koherensi pada novel. Ilmu merupakan bagian terpenting dalam proses kehidupan. Ilmu sekecil apapun akan berguna bagi orang yang menghargainya dan bagi orang yang tidak menghargainya walau sebesar apapun akan terasa sedikit. Peneliti berharap masyarakat dapat lebih mencintai sastra baik itu puisi, novel, atau dalam bentuk apapun karena bagaimana dalam sastra terdapat banyak orang yang mencurahkan semangat dan pesannya dalam bentuk tulisan.

\section{METODE}

Dalam penelitian ini, peneliti menggunakan pendekatan kualitatif dengan metode penelitian analisis isi/analisis konsep isi. Menurut Ratna (dalam Sulaeman dan Goziyah, 2019:186) isi dalam metode analisis isi terdiri atas dua macam, yaitu isi laten dan isi komunikasi. Isi laten adalah isi yang terkandung dalam dokumen dan naskah, sedangkan isi komunikasi adalah pesan yang terkandung sebagai akibat komunikasi yang terjadi. Sedangkan menurut Arifin E. Zaenal,7 et al (2015: 204-205) analisis isi merupaka metode analisis konten wacana yang dipakai untuk menganalisis isi wacana. Peneliti wacana dengan kajian analisis konten wacana juga dapat membuat inferensi (kesimpulan) yang bisa ditiru dan sahih dengan memerhatikan konteks. Analisis konten wacana bisa digunakan untuk menyusun interpretasi penelitian yang sesuai dan komprehensif. Analisis konten wacana sensitive konteks. Oleh karena itu, analisis ini dapat digunakan untuk memproses bentuk-bentuk simbolik. Peneliti bisa memberi makna pada data berupa kalimat, paragraf, atau seluruh wacana dengan mempertimbangkan dan memformulasikan semua itu pada konteks (tempat, waktu, situasi ketika peristiwa terjadi) yang melingkupi data itu. Tiga tujuan utama penggunaan analisis isi yaitu untuk mendeskripsikan data, menguji hipotesis, dan membuat inferensi. Sumber data 
penelitian ini menggunakan kutipan dalam novel Guru Aini karya Andrea Hirata. Teknik pengumpulan data dengan melakukan analisis pada novel Guru Aini, menentukan kutipan dalam novel berdasarkan hubungan-hubungan koherensi yang akan diteliti, mendeskripsikan kutipan sesuai dengan hubungan koherensi yang ditentukan, dan menarik kesimpulan dari hasil penelitian (Sulaeman dan Goziyah, 2019: 186). Zuchdi (dalam Sulaeman dan Goziyah, 2018: 186) mengemukakan secara procedural, metode analisis isi terdiri dari empat langkah utama, yaitu pengadaan data, reduksi data, inferensi dan analisis.

\section{HASIL DAN PEMBAHASAN}

Keutuhan sebuah wacana tidak hanya dilihat dari segi kohesinya saja, koherensi pada wacana berperan penting dalam membentuk kepaduannya. Menurut Jorgensen dan Louise (2010: 50) wacana merupakan usaha untuk menghentikan tergelincirnya hubungan antara satu tanda dengan tanda yang lain dan dengan demikian merupakan upaya untuk menciptakan sistem makna yang padu. Artinya wacana memiliki fungsi sebagai penghubung sistem makna antar kalimat agar memiliki kepaduan dan kesatuan antar setiap kalimat atau klausa sehingga ikatan makna yang terjalin akan menjadi kuat dan tegas. Tujuan pemakaian aspek koherensi dalam suatu wacana adalah untuk menciptakan keserasian, urutan yang tepat, dan kelogisan. Keserasian dilihat dari kesatuan wacana yang berkaitan dengan hubungan preposisinya. Urutan yang tepat menandakan susunan yang sistematis dari penyusunan wacana dalam rangka menjaga hubungan antar kalimat agar saling bertautan dan tidak terputus-putus. Kelogisan dimaksudkan untuk makna dalam wacana. Makna yang jelas, masuk akal, wajar dan mudah dimengerti dapat menimbulkan kesamaan pemikiran antara penulis dan pembaca untuk mencapai tujuan penulisan. Wacana yang padu dapat dilihat dari segi kekoherensiannya. Pada novel Guru Aini karya Andrea Hirata ditemukan koherensi yang terdisi atas : hubungan pertentangan, hubungan generik-spesifik, hubungan perbandingan, hubungan sebab akibat, hubungan tujuan, dan hubungan rujukan. Hubungan-hubungan tersebut membentuk kekoherensian pada novel yang dikuatkan berdasarkan kalimat-kalimat didalamnya sebagai pendukung keutuhan wacana yang ada pada novel tersebut. Aspek semantik yang membentuk kekoherensian pada novel Guru Aini karya Andrea Hirata adalah sebagai berikut :

\section{Hubungan Pertentangan}

Pada hubungan pertentangan perlwanan, bagian kedua merupakan perlawanan terhadap implikasi dari bagian pertama. Konjungtor yang digunakan, misalnya sebaliknya, akan tetapi, namun, padahal, walaupun demikian, walaupun begitu, meskipun begitu, meskipun demikian, bagaimanapun, walaupun demikian, sebaiknya, meskipun begitu, lain halnya (Arifin dkk, 
2015: 82). Berikut kutipan dalam novel Guru Aini karya Andrea Hirata yang menyatakan hubungan pertentangan :

Saat itu Laila tahu, bahwa Desi Istiqomah adalah seorang minimalis. Namun Desi menerima kedua ekor ayam itu.

Dari bangku-bangku kosong di depannya dia mendengar riuh-rendah suara murid-murid, ribut namun merdu di telinganya.

Sesungguhnya Aini tak pernah bermaksud memusuhi matematika, tapi matematika sendiri yang tak mau berkawan dengannya.

Semakin eksentrik karena Guru Desi selalu mengajar bersepatu olahraga putih bergaris-garis merah yang dulu dibelikan ayahnya dan telah dipakainya sejak dia meninggalkankotanya di tengah Sumatra sana. Meski sepatu itu tak pernah match dengan busana muslimahnya, dia tidak prduli.

Hubungan koherensi pertentangan yang digunakan pada kalimat-kalimat di atas ditandai oleh penggunaan kata namun, meski, dan tapi yang menunjukan hubungan koheren antar kalimat atau antar klausa sebagai kata hubung.

\section{Hubungan Generik-spesifik}

Hubungan ini ditandai oleh salah satu bagian memeberikan pernyataan generik, bagian yang lain menjelaskan detailnya (Arifin dkk, (2015: 85). Berikut kutipan dalam novel Guru Aini karya Andrea Hirata yang menyatakan hubungan generik-spesifik :

Tengoklah dirimu, Desi, semampai, ramping, peringkat satu di sekolah, juara renang, cantik bukan buatan. Kalua kuliah di Jakarta, kau bisa sekalian menjadi model busana muslimah, sedang digemari sekarang. Bisa pula menjadi atlet renang.

Hubungan koherensi generik-spesifik yang digunakan pada kalimat di atas menjelaskan kekhasan sifat dan pribadi seorang perempuan bernama Desi secara spesifik.

\section{Hubungan Perbandingan}

Hubungan perbandingan adalah membandingkan antar isi kedua bagian kalimat atau isi antara dua buah kalimat dalam satu wacana. Piranti perbandingan digunakan untuk menunjukan adanya hubungan persamaan atau perbedaan antara bagian yang satu dengan bagian yang lain Goziyah, 2018: 23). Berikut kutipan dalam novel Guru Aini karya Andrea Hirata yang menyatakan hubungan perbandingan : 
Desi berkebaya, dan tetap memakai sepatu olahraga putih itu. Dia tampak seperti Putri Melayu yang mau ikut lomba lari.

Mereka tahu, meskipun aneh dan ganjil penampilannya, Bu Desi jauh, jauh lebih cerdas dari mereka.

Di dalam kelas Desi benar-benar menemukan dirinya seperti yang selalu diinginkannya, yaitu menjadi seperti Guru Marlis, guru kesayangannya, guru yang membuatnya ingin menjadi guru.

Berbeda dengan murid lain, anak kuru situ mampu melihat satu persoalan dari banyak sisi.

Hubungan koherensi perbandingan yang terdapat pada kalimat-kalimat diatas menyatakan perbandingan kemiripan yang ditandai dengan kata seperti, perbandingan spesifik yang ditandai dengan kata jauh lebih, dan perbandingan perbedaan yang ditandai dengan kata berbeda dengan.

\section{Hubungan Sebab Akibat}

Hubungan sebab-akibat ditandai oleh bagian yang satu menyatakan sebab dan bagian yang lain menjadi akibat. Konjungsi yang digunakan, misalnya jika, karena, oleh sebab itu, jadi, akibatnya, oleh karena itu, maka, dengan demikian (Arifin dkk, 2015: 80). Berikut kutipan dalam novel Guru Aini karya Andrea Hirata yang menyatakan hubungan sebab-akibat :

Kalaupun dia berminat, Ibu Amanah juga yakin Desi bisa lulus tes masuk universitas mana pun di negeri ini, fakultas apa pu. Sebab nilai ijazahnya sangat cemerlang.

Dalam pemikiran Guru Desi, jika dia berhasil menemukan dan mendidik seorang anak Kampung Ketumbi menjadi genius matematika, maka anak-anak Kampung Ketumbi lainnya akan melihat bahwa mereka pun bisa meraih sesuatu yang selalu mereka bayangkan tak mungkin dapat mereka raih.

Berdasarkan penelitian antah-berantah, umumnya idealisme anak muda yang baru tamat dari perguruan tinggi bertahan paling lama 4 bulan. Setelah itu mereka akan menjadi pengeluh, penggerutu, dan penyalah seperti banyak orang lainnya, lalu secara menyedihkan terseret arus deras sungai besar rutinitas, basa-basi birokrasi lalu tunduk patuh pada sistem yang buruk, adakalanya korup, yang jangankan akan mereka ubah, seperti cita-cita mereka semula, mempertanyakan saja mereka sungkan. Demikian buruknya, tanpa mereka sadari sistem itu dapat membentuk 
mereka menjadi orang yang snagat cemas akan kelangsungan operasional periuk belanga mereka semata.

Nurjamin, kawan Desi lainnya, yang orangnya tak tegaan, terpaksa menghukum muridnya berdiri di pojok kelas karena tak becus mengerjakan soal di papan tulis. Ayahnya itu pedagang kaki lima mainan anak-anak. Seorang penyayang keluarga. Selalu tampak sehat walafiat tak kurang suatu apa, tiba-tiba kolaps. Aini terpukul karena sangat dekat dengan ayahnya. Mendadak dia yang selalu ceria, yang tawanya pandai menular, jadi pemurung.

Hubungan koherensi pada kalimat-kalimat diatas dinyatakan dalam kata sebab, maka, demikian, karena, dan jadi. Kata hubung tersebut menimbulkan kekoherenan antar kalimat dan klausa.

\section{Hubungan Tujuan}

Hubungan tujua ditandai oleh salah satu bagian menjawab pertanyaan, "Bagaimana caranya untuk mencapai tujuan ?" (karena tujuan itu belum tentu tercapai) (Arifin dkk, 2015: 86). Berikut kutipan dalam novel Guru Aini karya Andrea Hirata yang menyatakan hubungan tujuan :

Waktu adalah ibu matematika, Nong. Angka berbaris-baris dalam deret hitung, deret ukur, dan deret waktu. Mereka yang tak dapat merasakan waktu, takkan dapat belajar matematika. Karena waktu memberi nasihat terbaik dalam belajar matematika, yakni kesabaran dalam memahami sesuatu, ketangguhan dalam menghadapi kesulitan apa pun, dan obsesi pada presisi, pada presisi tertinggi.

Hubungan koherensi tujuan pada kalimat tersebut menyatakan sebuah tujuan untuk memahami waktu dalam belajar matematika yang disampaikan Bu Desi dengan gambaran pertanyaan "Bagaimana Aini dapat memahami matematika, sedangkan dia tak dapat merasakan waktu dari setiap detik jam yang sedang berjalan ?" pada novel.

\section{Hubungan Rujukan}

Hubungan rujukan ditandai dengan pernyataan yang merujuk pada hal yang sama pada dua bagian kalimat atau pada dua kalimat dalam satu wacana. Berikut kutipan dalam novel Guru Aini karya Andrea Hirata yang menyatakan hubungan rujukan :

Kau ini sudahlah bodoh! Miskin! Culas pula! Apa jadinya bangsa ini kalua pelajarnya saja curang! Sekolah ini bukan pembibitan koruptor, Man! Sudah 
berkali-kali kau tertangkap basah menyontek, Man! Tengoklah kau itu, Man! Mukamu rusuh! Jiwamu lusuh! Pikiranmu kumuh!

Hubungan koherensi rujukan pada kalimat di atas merujuk pada sebuah pernyataan seseorang terhadap orang lainnya dengan sifat yang menguatkan maksud dari tulisan untuk mengetahui makna dalam kalimat pada sebuah wacana yang membuatnya jadi koheren.

\section{SIMPULAN}

Berdasarkan hasil analisis yang telah dilakukan bahwa wacana dalam novel Guru Aini karya Andrea Hirata memiliki bahasa yang khas dalam membentuk kalimat yang koheren. Koherensi yang digunakan untuk membangun keutuhan dan kepaduan wacana dalam novel tersebut berupa : (1) hubungan pertentangan, (2) hubungan perbandingan, (3) hubungan generik-spesifik, (4) hubungan sebab-akibat, (5) hubungan tujuan, (6) hubungan rujukan. Penggunaan hubungan koherensi pada novel Guru Aini karya Andrea Hirata tersebut memiliki kepaduan makna yang baik dalam penulisan wacananya dengan disertai gaya penulisan yang khas menjadikan novel tersebut bernilai dan berpotensi. Bernilai dimaksudkan sebagai sumber pengetahuan dan wawasan bagi para pembaca berdasarkan makna yang terkandung dalam novel tersebut. Berpotensi adalah kata yang menggambarkan bagaimana novel ini dapat membuat perubahan pada pola pikir pembaca terhadap karya sastra untuk dijadikan sebagai bahan bacaan yang menarik dan tidak sulit dipahami.

\section{REFERENSI}

Darmawati.2012.Kohesi dan Koherensi Wacana Narasi dalam Modul Karya Guru.Jurnal $\begin{array}{llllll}\text { Retorika.SMPN } & 1 & \text { Bulukumba.Vol } & 8 & \text { N0. } & 2.2012 .\end{array}$ https://ojs.unm.ac,id/retorika/article/view/3621

Djajasudarma, Fatimah.2010.Wacana.Bandung: PT Refika Aditama

E. Zaenal, Arifin dkk.2015.Wacana Transaksional dan Interaksional dalam Bahasa Indonesia.Tangerang: Pustaka Mandiri

Elfiana, Annisa dan Muhammad Farkhan.2018.Relasi Koherensi Wacana Tulis: Studi Kasus Pada Editorial Koran The Jakarta Post.Jurnal UIN Jakarta.Universitas Islam Negeri Syahid Jakarta.Vol 25 No 2 2018.http://journal.uinjkt.ac.id/index.php/alturats/article/view/13299/pdf

Goziyah.2018.Studi Wacana Bahasa Indonesia (Kajian Wacana Kritis).Tangerang: UMT Press 
Hawa, Masnuatul.2014.Novel Sepatu Dahlan Karya Khrisna Pabichala Analisis Psikologi Sastra dan Nilai Pendidikan.Jurnal Edutama. IKIP PGRI Bojonegoro.Vol 1 No. 22014 Hirata, Andrea.2020.Guru Aini.Yogyakarta: PT Bentang Pustaka

Indrawati, Widaningsih dwi.2015.Analisis Kohesi dan Koherensi dalam Novel Krikil-Krikil Pasisir Karya Tamsir AS.Jurnal Program Studi Pendidikan Bahasa dan Sastra $\begin{array}{llllll}\text { Jawa.Universitas } & \text { Muhammadiyah } & \text { Purwerejo.Vol } & 7 & \text { No. } & 4\end{array}$ 2015.https://scholar.google.ac.id/scholar?hl=id\&as_sdt=0\%2C5

$\& \mathrm{q}=$ analisis+koherensi+pada+novel\&oq=\#d=gs_qabs\&u=\%23p\%3Dggl2xPGOulwj

Joegensen, Marianne W. dan Louise J. Phillips. 2010.Analisis Wacana Teori dan Metode. Yogyakarta: Pustaka Pelajar

Maulana, Putu Ari Putra dan Madia, Made.2019.Analisis Koherensi dan Kohesi Teks Deskripsi.Journal of Arts and Humanities.UNUD.Vol 23 2019.https://ojs.unud.ac.id/index.php/sastra/article/view/48641

Palupi, Digna.2013.Perbandingan Kohesi dan Koherensi Dalam Karangan Deskriptif Siswa Kelas X SMK Jurusan Teknik Otomotif Kendaraan Ringan (TOKR) dan Rekayasa Perangkat Lunak (RPL) Berdasarkan Pada Kemampuan Berpikir Analisis Sintesis Di Bidang Program Keahlian.Jurnal Seloka.Universitas Negeri Semarang.Vol 02 No 01 2013.https://journal.unnes.ac.id/sju/index.php/seloka/article/view/1317

Sulaeman, Agus dan Goziyah.2018.Metodologi Penelitian Bahasa dan Sastra.Jakarta Timur: Edu Pustaka

Suryaningsih, Rina.2014.Kajian Kohesi dan Koherensi Dalam Novel Lintang Karya Ardini Pangastuti.Jurnal Program Studi Pendidikan Bahasa dan Sastra Jawa.Universitas Muhammadiyah Purworejo.Vol 05 No 02 2014.https://scholar.google.co.id/scholar ?hl=id\&as_sdt=0\%2C5\&q=analisis+koherensi+pada+novel $\&$ oq $=$ kohere\#d=gs_qabs\&u= $\% 23 \mathrm{p} \% 3 \mathrm{D} 2 \mathrm{OOGKBoKJmMJ}$

Utami, Puji.2012.Wacana Novel Jaring Kalamangga Karya Suparto Brata Tinjauan KohesI dan Koherensi.Skripsi.Fakultas Sastra dan Seni Rupa.Jurusan Sastra Daerah.Universitas Sebelas

Maret.Surakarta.https://scholar.google.co.id/scholar?star=30\&q=analisis+koherensi+pad a+novel\&hl=id\&as_sdt=0,5\#d=gs_qabs\&u=\%23p\%3DgolQgkl+NU4J 